\title{
ROS-mediated NLRP3 inflammasome activation participates in the response against Neospora caninum infection
}

\author{
$\mathrm{Lu} \mathrm{Li}^{1+}$, Xiao-Cen Wang ${ }^{1 \dagger}$, Peng-Tao Gong ${ }^{1 \dagger}$, Nan Zhang ${ }^{1}$, Xu Zhang ${ }^{1}$, Shan Li ${ }^{1}$, Xin Li ${ }^{1}$, Shao-Xiong Liu', \\ Xiao-Xu Zhang ${ }^{1}$, Wei Li ${ }^{2}$, Jian-Hua Li ${ }^{1 *}$ and Xi-Chen Zhang ${ }^{1 *}$
}

\begin{abstract}
Background: Neospora caninum is an obligate intracellular protozoan that causes neosporosis, N. caninum infection is a major cause of abortion in cattle worldwide. Currently, specific treatment for neosporosis is not available. The NOD-like receptor family pyrin domain containing 3 (NLRP3) inflammasome is a cytoplasmic protein complex that plays an important role in host defense against $N$. caninum infection, but the underlying mechanisms are poorly understood.
\end{abstract}

Methods: The reactive oxygen species (ROS) inhibitor and the ROS inducer, wild-type (WT) and NLRP3-deficient peritoneal macrophages or mice were used to investigate the role of ROS in NLRP3 inflammasome activation and controlling parasite burdens. ROS production, cell death and cell viability, production of inflammasome-mediated IL-1 $\beta$ or IL-18, cleavage of caspase-1 and NLRP3 expression, as well as parasite burdens were detected.

Results: In vitro, N. caninum induced ROS generation in a dose-dependent manner in peritoneal macrophages. The pretreatment of ROS inhibitor N-acetyl-L-cysteine (NAC) significantly attenuated N. caninum-induced ROS production, $\mathrm{LDH}$ release, IL-1 $\beta$ secretion and NLRP3 expression, whereas $N$. caninum proliferation was notably increased. In contrary, the ROS inducer pyrogallol (PG) significantly enhanced ROS production and NLRP3 inflammasome activity and decreased the parasite burden in N. caninum-infected peritoneal macrophages. NADPH-dependent ROS-mediated NLRP3 inflammasome activation induced by N. caninum can also be confirmed by using the NADPH oxidase inhibitor diphenyleneiodonium chloride (DPI). However, the NAC or DPI pre-treatment or PG treatment did not significantly alter N. caninum-induced inflammasome activities and parasite proliferation in N/rp3 ${ }^{-/-}$peritoneal macrophages. In vivo, IL-18 releases in serum and parasite burdens in peritoneal exudate cells were significantly increased in PG-treated WT mice after infection with N. caninum; however, IL-18 productions and parasite burdens were not changed in PGtreated ${\mathrm{N} / r p 3^{-/-}}$mice. Furthermore, PG treatment in WT mice infected with N. caninum significantly decreased the mortality, weight loss and parasite burdens in tissues and histopathological lesions.

Conclusions: Neospora caninum-induced NADPH-dependent ROS generation plays an important role in NLRP3 inflammasome activation and controlling parasites. The ROS inducer PG can control N. caninum infection mainly by promoting NLRP3 inflammasome activation. ROS-mediated NLRP3 inflammasome axis can be a potential therapeutic target for neosporosis.

Keywords: Neospora caninum, NLRP3 inflammasome, Reactive oxygen species, Pyrogallol, Host defense

\footnotetext{
*Correspondence: jianhuali7207@163.com;xczhang@jlu.edu.cn

${ }^{\dagger} \mathrm{Lu}$ Li, Xiao-Cen Wang and Peng-Tao Gong contributed equally to this

study

1 Key Laboratory of Zoonosis Research, Ministry of Education, College of Veterinary Medicine, Jilin University, Changchun 130062, PR China

Full list of author information is available at the end of the article
}

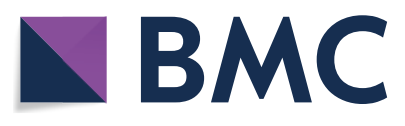

(c) The Author(s) 2020. This article is licensed under a Creative Commons Attribution 4.0 International License, which permits use, sharing, adaptation, distribution and reproduction in any medium or format, as long as you give appropriate credit to the original author(s) and the source, provide a link to the Creative Commons licence, and indicate if changes were made. The images or other third party material in this article are included in the article's Creative Commons licence, unless indicated otherwise in a credit line to the material. If material is not included in the article's Creative Commons licence and your intended use is not permitted by statutory regulation or exceeds the permitted use, you will need to obtain permission directly from the copyright holder. To view a copy of this licence, visit http://creativecommons.org/licenses/by/4.0/. The Creative Commons Public Domain Dedication waiver (http://creativecommons.org/publicdomain/zero/1.0/) applies to the data made available in this article, unless otherwise stated in a credit line to the data. 


\section{Background}

Neospora caninum is an intracellular protozoan parasite [1-3], mainly causes neuromuscular disorders in canines, and abortion and stillbirth in ruminants. Neosporosis is considered as one of the main infectious causes of abortion in cattle, as well as stillbirth and the birth of weak calves, leading to a significant economic burden on the beef and dairy industries worldwide [4]. Currently, neither effective vaccines nor drugs have been developed for the prevention and treatment of neosporosis due to the elusive anti- $N$. caninum immune mechanisms in the hosts $[5,6]$. Neospora caninum has three infectious stages (tachyzoites, bradyzoites and sporulated oocysts). During acute $N$. caninum infection, tachyzoites disseminate via the blood stream and lymphatic system, and trigger the innate and the adaptive immune response [7]. It is reported that the pathogenesis of acute neosporosis is closely related to the rapid proliferation of $N$. caninum tachyzoites in cells [8]. The host innate immune response plays a critical role in recognizing pathogen and inhibiting initial parasite replication, subsequently mediating appropriate adaptive immune response to promote the host resistance to this infection $[9,10]$. The patternrecognition receptors (PRRs) of innate immune cells are activated in $N$. caninum infection, such as TLR2 [11] and TLR3 [12] from the Toll-like receptors family (TLRs), NOD2 [9] and NLRP3 [8] from the NOD-like receptors family (NLRs). These PRRs can promote host defense to $N$. caninum infection or contribute to the pathogenesis. We have previously found that the sensor NLRP3 was upregulated and NLRP3 inflammasome was activated in $N$. caninum-infected peritoneal macrophages (PMs), and this pathway functioned in the elimination of $N$. caninum [8]. However, its molecular activation mechanisms need to be further explored.

The NLRP3 inflammasome is a multimeric protein complex found in the cytosol. The sensor NLRP3 interacts with the adaptor molecule ASC (apoptosis-associated speck-like protein), and the caspase recruitment domain (CARD) of ASC binds to the CARD domain of caspase-1 via protein-protein domain interactions to form the NLRP3 inflammasome [13, 14]. Inflammasome activation leads to the activation of caspase- 1 , cleavage of active interleukin (IL)- $1 \beta$ and IL-18, and caspase-1-dependent cell death (known as pyroptosis) [15]. The NLRP3 inflammasome is activated by various pathogen-associated molecular patterns (PAMPs) including microbial nucleic acids or proteins, and hostderived danger-associated molecular patterns (DAMPs) such as uric acid crystals [16-18]. Multiple cell-signaling mechanisms can participate in NLRP3 activation, including the release of reactive oxygen species (ROS), potassium efflux, lysosomal damage, and mitochondrial destabilization or damage [19]. Additionally, NLRP3 could be directly regulated by ROS [20].

ROS generation has been identified as a key factor in NLRP3 inflammasome activation in parasitic infections by those such as Plasmodium falciparum [21], Trypanosoma cruzi [22], and Toxoplasma gondii [13, 23]. ROS has been implicated in the regulation of many important cellular events, including proliferation, differentiation, immune response, cell growth, and cell survival [24, 25]. Our previous study showed that $N$. caninum tachyzoites can induce NADPH oxidase-dependent ROS generation in canine polymorphonuclear neutrophils [26]. As the $\mathrm{NADPH}$ oxidase-dependent ROS generation contributes to Nalp3 inflammasome activation [27], it is therefore conceivable that $N$. caninum-infected PMs undergo NLRP3 inflammasome activities due to ROS production. Nevertheless, whether ROS is involved in NLRP3 inflammasome activation during $N$. caninum infection and how this axis controls the parasite burden, remain to be clarified. To the best of our knowledge, this is the first study that investigates ROS-mediated NLRP3 inflammasome activation and its role in controlling $N$. caninum replication in $N$. caninum-infected PMs, and assesses the potential of ROS inducer pyrogallol (PG) in activating ROS-dependent NLRP3 inflammasome and eliminating parasites in vitro and in vivo.

\section{Methods \\ Animals}

Wild-type (WT) female C57BL/6 mice (6-8 weeks-old) were purchased from the Changsheng Experimental Animal Center (Benxi, China), and NLRP3-deficient female mice backcrossed onto the C57BL/6 genetic background were obtained from the Jackson Laboratory (Bar Harbor, ME, USA). The mice were maintained in specific pathogen-free conditions and housed in isolator cages in the animal house of the Laboratory Animal Center of Jilin University. Drinking water and food were supplied ad libitum.

\section{Parasites and cell culture}

Neospora caninum (Nc-1 isolate) tachyzoites were maintained by serial passages in Vero cells, which were cultured in Roswell Park Memorial Institute (RPMI)-1640 medium (Life Technologies, Grand Island, NY, USA) supplemented with $2 \%$ heat-inactivated fetal bovine serum (FBS; Biological Industries, Ltd., Beit HaEmek, Israel), $2 \mathrm{mM} \mathrm{L}$-glutamine, $100 \mathrm{U} / \mathrm{ml}$ penicillin, and 100 $\mu \mathrm{g} / \mathrm{ml}$ streptomycin (all from Life Technologies), and they were incubated at $37{ }^{\circ} \mathrm{C}$ under $5 \% \mathrm{CO}_{2}$. Neospora caninum tachyzoites were harvested when $80 \%$ of Vero cells were lysed, parasites and Vero cell debris were then treated with a 27 gauge needle, and Vero cell debris were 
removed by gradient density centrifugation with a $40 \%$ Percoll (GE Healthcare, Uppsala, Sweden) solution (v/v), centrifuged at $1500 \times g$ for $30 \mathrm{~min}$, then the pellet of $N$. caninum tachyzoites was harvested and washed twice with RPMI-1640 (centrifuged at $900 \times g$ for $10 \mathrm{~min}$ ) [8], and the $N$. caninum concentration was measured by using a hemocytometer. Female WT and $\mathrm{Nlrp}^{-/-}$mice were inoculated intraperitoneally with $3 \mathrm{ml}$ of $5 \%$ thioglycolate medium (BD Biosciences, New Zealand, USA) for 4 days, and the mice were humanely euthanized [28] and soaked with $75 \%$ alcohol for $10 \mathrm{~min}$, PMs were obtained by flushing the peritoneal cavity twice with cold phosphate-buffered saline (PBS), then the cell suspension was centrifuged at $1000 \times g$ for $10 \mathrm{~min}$, and washed twice with PBS [29]. The PMs were cultured in R-10\% medium (comprising RPMI supplemented with $10 \%$ heat-inactivated FBS, $2 \mathrm{mM}$ L-glutamine, $100 \mathrm{U} / \mathrm{ml}$ penicillin, and $100 \mu \mathrm{g} / \mathrm{ml}$ streptomycin) for at least $12 \mathrm{~h}$.

\section{Experimental infection and stimulation}

PMs were isolated from WT or $N \operatorname{lrp3} 3^{-/}$mice and infected with $N$. caninum at a multiplicity of infection (MOI) of 3:1, 2:1 or 1:1 (parasite: cell) in R-1\% medium for 2, 4 or $8 \mathrm{~h}$, then PMs were washed twice with PBS to remove non-adhered parasites. In the experimental group, cells were pre-treated with the ROS inhibitor NAC for $1 \mathrm{~h}$ (5 mM; Selleck, Shanghai, China), or the NADPH oxidase inhibitor diphenyleneiodonium chloride (DPI, $10 \mu \mathrm{M}$; Selleck) for $2 \mathrm{~h}$ [30]. Additionally, at 2, 4 or $8 \mathrm{~h}$ post-infection (pi), the medium was changed to fresh medium with or without the ROS inducer pyrogallol (PG; Selleck). PMs cultured with the equivalent volume of $\mathrm{R}-1 \%$ medium was used as a negative control. Adenosine triphosphate (ATP) is a NLRP3 inflammasome inducer [31], so PMs in positive control group were pre-treated with $N$. caninum and then stimulated with $5 \mathrm{mM}$ ATP (Sigma-Aldrich, Shanghai, China) for $30 \mathrm{~min}$. At 5, 24 or $36 \mathrm{~h}$ post-infection, cells and supernatants were collected for subsequent experiments, as described below.

\section{Anti-N. caninum activity of PG in vivo}

WT and $\mathrm{Nlrp}^{-/-}$female mice were used to establish an animal model of acute $N$. caninum infection. The two kinds of mice were each randomly divided into three groups: PBS-treated mice; N. caninum-infected mice; and N. caninum-infected with PG-treated mice (SigmaAldrich). Each group consisted of 5 mice. PG was dissolved in PBS. The mice were intraperitoneally injected with $2.5 \times 10^{7} \mathrm{~N}$. caninum tachyzoites or the same volume of PBS. From day 2 pi, mice in the infection groups were intraperitoneally injected daily with $0.5 \mathrm{ml}$ of 75 $\mathrm{mg} / \mathrm{kg}$ PG [32, 33] for 5 days, and the remaining mice were administered the same volume of PBS. On day 8 , peritoneal exudate cells were harvested as previously described [34], and serum, heart, liver, spleen, lung, kidney, and brain samples were collected. Fragments of these tissues were immediately fixed in $10 \%$ formalin buffer solution and routinely processed for paraffin embedding, and histopathological changes were examined with H\&E staining under light microscopy.

\section{Intracellular ROS detection}

Intracellular ROS generation in PMs (MOI of 3:1 or 1:1) was measured using the 2,7 dichlorofluorescein diacetate (DCFH-DA) (Sigma-Aldrich). PMs were plated in triplicate in 96-well plates at a density of $5 \times 10^{4}$ cells/well and 6 -well plates at a density of $3 \times 10^{6}$ cells/well. PMs were pre-treated with NAC (for $1 \mathrm{~h}$ ), or DPI (for $2 \mathrm{~h}$ ), then incubated with $N$. caninum for $2 \mathrm{~h}$, washed twice with RPMI 1640 to remove non-adhered parasites, then cultured in fresh $\mathrm{R}-1 \%$ medium for $3 \mathrm{~h}$. In the PG treatment group, fresh R-1\% medium was added with PG (the dilutions included concentrations from $15,30,60$ or $80 \mu \mathrm{M}$ ). PMs were stimulated with zymosan $(1 \mathrm{mg} / \mathrm{ml}$; SigmaAldrich) as a positive control. After incubation, the supernatant was removed, and the PMs were incubated with the DCFH-DA for $20-30 \mathrm{~min}$ at $37^{\circ} \mathrm{C}$, followed by 3 washes with FBS-free RPMI in the dark. PMs in 96-well plates were assessed with a multifunctional fluorescence microplate reader (M2e, Molecular Devices, Sunnyvale, CA, USA), using $488 \mathrm{~nm}$ emission and $525 \mathrm{~nm}$ excitation. And PMs collected from 6-well plates were analyzed using an FACSAria flow cytometer (BD Biosciences).

\section{Lactate dehydrogenase (LDH) release assay}

Pyroptosis was analyzed by detecting the activity of LDH released into the cell supernatants (collected from $3 \times 10^{6}$ cells) at different treatment for 24 or $36 \mathrm{~h}$ using an $\mathrm{LDH}$ assay (Roche Diagnostics, Mannheim, Germany) according to the manufacturer's protocol. The absorbance was measured at $490 \mathrm{~nm}$. The percentage of LDH release was calculated as follows: $\left(\mathrm{LDH}_{\text {infected }}-\mathrm{LDH}_{\text {control }}\right) /\left(\mathrm{LDH}_{\text {total }}\right.$ lysis $\left.-\mathrm{LDH}_{\text {control }}\right) \times 100$.

\section{Cell viability assay}

The toxic effects of PG in PMs were examined using a Cell Counting Kit 8 (CCK-8) (Dojindo Laboratories, Kumamoto, Japan), according to the manufacturer's instructions. PMs were seeded in triplicate in 96-well plates $\left(1 \times 10^{4}\right.$ cells/well), cultured in $\mathrm{R}-10 \%$ medium for $24 \mathrm{~h}$. Then PMs were treated with 15, 30, 60 and 80 $\mu \mathrm{M}$ PG diluted in R-1\% medium. Negative control PMs were treated with R-1\% medium without the addition of PG. After 24 and $48 \mathrm{~h}$ of treatment, $10 \mu \mathrm{l}$ of CCK- 8 reagent was added to each well and incubated for $1.5 \mathrm{~h}$. The absorbance was measured at $450 \mathrm{~nm}$. 


\section{Western blotting}

PMs were seeded in 6-well plates at a density of $3 \times$ $10^{6}$ cells/well, and pre-treated for $1 \mathrm{~h}$ with NAC, then infected with $N$. caninum (MOI of 3:1 2:1 or 1:1). In some experiments, PMs were incubated with $N$. caninum for $8 \mathrm{~h}$, then treated with PG at different concentrations. At 24 or $36 \mathrm{~h}$ post-infection, the cell lysates and supernatants were collected and assessed by western blotting, as described previously [27]. The following primary antibodies were incubated overnight at $4{ }^{\circ} \mathrm{C}$ : anti-mouse IL-1 $(\mathrm{p} 17 ; 1 / 1,000 ;$ AF-401; R\&D, Minneapolis, MN, USA); anti-mouse caspase-1 (p20; 1/1,000; AG-20B-0042; Adipogen, Liestal, Switzerland); anti-NLRP3 (1/1,000; AG-20B-0014, Adipogen); and anti-mouse $\beta$-actin (1/2,000; 60008-1; Proteintech, Wuhan, China). Secondary horseradish peroxidase (HRP)-conjugated rabbit antigoat or anti-mouse IgG (1/5,000; Proteintech) was then added for $1 \mathrm{~h}$ at room temperature (RT). Finally, proteins were visualized using an Enhanced chemiluminescence (ECL) Western Blot Detection System (Clinx Science Instruments, Co., Ltd., Shanghai, China).

\section{Cytokine measurement assay}

Active IL-1 $\beta$ in cell supernatants (collected from $3 \times$ $10^{6}$ PMs) were measured using the mouse IL- $1 \beta$ ReadySet-Go Kit, and IL-18 in the mice serum were measured using the mouse IL-18 Ready-Set-Go Kit (eBioscience, San Diego, CA, USA), according to the manufacturer's instructions.

\section{Real-time quantitative PCR (qPCR)}

PMs were seeded in 12 -well plates at a density of $1 \times 10^{6}$ cells/well, and pre-treated for $1 \mathrm{~h}$ with NAC, then were infected with $N$. caninum (MOI of 1:1). Where required, the PMs were infected $N$. caninum for $4 \mathrm{~h}$, then treated with PG at different concentrations. At $24 \mathrm{~h}$ post-infection, the cells were collected. For the in vivo assays, mice were intraperitoneally injected with $2.5 \times 10^{7} \mathrm{Nc}-1$ tachyzoites, and peritoneal exudate cells in the peritoneal lavage fluid at the initial infection site, along with heart, liver, spleen, lung, kidney, and brain samples, were collected at day 8 pi All samples were stored at $-20^{\circ} \mathrm{C}$. The parasite replication in cells and tissues were monitored as previously described [35] by real-time qPCR. DNA from $8 \times 10^{7} \mathrm{Nc}-1$ tachyzoites or from infected cells and tissues was extracted using a Genomic DNA Extraction Kit (Tiangen, Beijing, China) according to the manufacturer's standard protocol. The DNA (200 ng from cells and 500 ng from tissues) samples were subsequently used as the templates in qPCR analyses. A 76-bp fragment of N. caninum DNA was amplified using the following primers: forward (5'-ACT GGA GGC ACG CTG AAC AC-3'); reverse (5'-AAC AAT GCT TCG CAA GAG GAA-3').
The number of parasites was determined based on a standard curve obtained using DNA from serial dilutions of $N$. caninum tachyzoites $\left(6.56-6.56 \times 10^{6}\right.$ parasites).

\section{Immunofluorescence and replication assay}

PMs $\left(5 \times 10^{5}\right.$ cells/well $)$ were placed on coverslips in 24-well plates overnight. PMs were challenged with $N$. caninum tachyzoites (MOI of $1: 1$ ) for $4 \mathrm{~h}$, then treated with PG. When required, PMs were pre-treated for 1 h with NAC before $N$. caninum infection (MOI of 1:1). At $24 \mathrm{~h}$ post-infection, PMs were rinsed 3 times in PBS, fixed with $4 \%$ paraformaldehyde for $20 \mathrm{~min}$ at RT, washed 3 times with PBS, permeabilized with $0.25 \%$ Triton-X-100 in PBS for $10 \mathrm{~min}$, washed in PBS, and blocked with $3 \%$ bovine serum albumin (BSA) in PBS for $2 \mathrm{~h}$ at RT. The PMs were incubated overnight at $4{ }^{\circ} \mathrm{C}$ with primary antibody antiserum against NcSAG1 (1:100; diluted using $1 \%$ BSA in PBS; this reacts with $N$. caninum) washed 3 times with PBS, then incubated for $1 \mathrm{~h}$ at RT with goat anti-rabbit fluorescein isothiocyanate (FITC)-conjugated secondary antibody (Proteintech) in the dark. The F-actin was labeled with tetramethylrhodamine isothiocyanate (TRITC)-phalloidin (Yeasen, Shanghai, China) for 30 min, and the nuclei were stained with 4',6-diamidino2-phenylindole (DAPI; Invitrogen, Carlsbad, CA, USA) for $10 \mathrm{~min}$. Images were captured using an Olympus FV1000 Laser Scanning Confocal Microscope (Japan). The infected cells were observed, the number of parasites in each parasitophorous vacuole was counted and at least 100 parasitophorous vacuoles were counted in the infected group.

\section{Statistical analysis}

Statistical significance was determined by using the Student's t-test or one-way ANOVA in SPSS 19.0 (SPSS Inc., Chicago, IL, USA), and data are shown as the mean \pm standard error of the mean (SE). All graphs were generated using GraphPad Prism 5 (GraphPad Software, Inc., San Diego, CA, USA). All experiments were performed 3 times with 3 technical replicates. $P$-values $<0.05$ were considered significant.

\section{Results}

Neospora caninum infection elicited ROS generation in PMs To investigate whether ROS is generated in N. caninuminfected PMs, we detected the level of ROS induced by various MOIs of $N$. caninum tachyzoites in PMs using a DCFH-DA fluorescent probe. Similar with the result of zymosan (positive control)-treated PMs, ROS generation was found in $N$. caninum-infected PMs, but was decreased by the pretreatment of ROS inhibitor NAC $\left(F_{(4,}\right.$ 10) $=366.85, P<0.0001$; Fig. 1a). To further confirm our observation, we examined ROS production by measuring 
the mean fluorescence intensity (MFI) of DCFH-DA. The results further showed that ROS production was significantly triggered by $N$. caninum in a dose-dependent manner. Meanwhile, ROS was significantly inhibited in $N$. caninum-infected PMs with NAC pretreatment $\left(F_{(4,10)}\right.$ $=125.79, P<0.0001$ ) (Fig. 1b, c). These results suggest that $N$. caninum induces ROS generation in PMs.

\section{ROS inhibitor NAC attenuated N. caninum-induced NLRP3 inflammasome activation and increased $N$. caninum proliferation in PMs}

To elucidate whether the ROS participates in NLRP3 inflammasome activation and the control of the parasite burden in $N$. caninum-infected PMs, PMs were pre-treated with the ROS inhibitor NAC, then the secretion of active IL-1 $\beta$ and the expression of NLRP3 were assessed by western blotting, inflammasome-dependent cell death was detected using an LDH assay. In addition, the parasite burden was monitored by qPCR using total DNA (200 ng) from N. caninum-infected PMs, and quantification of parasites in parasitophorous vacuoles of $N$. caninum-infected cells was carried out using confocal microscopy. Results showed that $N$. caninum induced inflammasome-dependent LDH release in PMs, while NAC significantly decreased LDH release $\left(F_{(2,6)}=125.7\right.$, $P<0.0001$; Fig. 2a). Additionally, NAC abrogated $N$. caninum-induced NLRP3 expression in cells and active IL-1 $\beta$ secretion in the supernatants (active IL-1 $\beta: F_{(5,12)}$ $=141.92, P<0.0001$ ) (Fig. 2b, c). Moreover, the percentage of $N$. caninum-infected PMs (assessed by confocal microscopy) was significantly increased in the NAC-pretreated group $\left(t_{(4)}=3.49, P=0.0251\right.$; Fig. $\left.2 \mathrm{~d}\right)$, and the parasite burden (assessed by confocal microscopy and qPCR) was also higher in the NAC-pre-treated group than that in the $N$. caninum infection-only group (Fig. 2e: $t_{(4)}=8.078, P=0.0013$; Fig. 2f: $t_{(4)}=3.384, P=0.0277$ ). The results showed that NLRP3 inflammasome activation was inhibited and the parasite burden was increased by NAC pretreatment in N. caninum-infected PMs. These data suggest that ROS plays a very important role in regulating NLRP3/ IL-1 $\beta$ and the control of intracellular parasite replication in N. caninum-infected PMs.

\section{ROS inducer PG inhibited $N$. caninum replication} by promoting NLRP3 inflammasome activation in vitro

To further explore the relationship between ROS and the NLRP3 inflammasome response to $N$. caninum infection in PMs, N. caninum-infected PMs were treated with the ROS inducer PG. We first analyzed the cytotoxicity of PG by treating PMs with PG at various concentrations (15, 30,60 and $80 \mu \mathrm{M}$ ) for 24 or $48 \mathrm{~h}$ and then performing the CCK- 8 assay. The results showed cell viability was not inhibited by PG treatment at concentrations of 15 or 30 $\mu \mathrm{M}$, while the opposite effect was observed at concentrations of 60 or $80 \mu \mathrm{M}\left(24 \mathrm{~h}: F_{(4,10)}=57.69, P<0.0001 ; 48\right.$ h: $F_{(3,8)}=187.38, P<0.0001$; Fig. 3a), but ROS generation in PMs was significantly increased in a dose-dependent manner $\left(F_{(4,10)}=93.05, P<0.0001\right.$; Fig. 3b). The PG treatment can greatly increase $N$. caninum-triggered intracellular ROS production compared with the infection-only group by the multifunctional fluorescence microplate reader $\left(F_{(9,20)}=363.87, P<0.0001\right.$; Fig. 3c). LDH release can be induced by $N$. caninum and indicate inflammasome-dependent cell death, and $N$. caninum induced LDH releases were significantly increased after PG treatment in a dose-dependent manner $\left(F_{(9,20)}=143.81, P<0.0001\right.$; Fig. 3d). In addition, in accord with the positive control (ATP) group, $N$. caninum induced active IL-1 $\beta$ secretions were also greatly increased by PG treatments $\left(F_{(10}\right.$, $\left.{ }_{22}\right)=555.95, P<0.0001$; Fig. 3e). The western-blot results show that NLRP3, cleavage of caspase- 1 and active IL-1 $\beta$ were significantly increased after PG treatment of $N$. caninum-infected PMs for $36 \mathrm{~h}$; the effects of PG were most notable at $30 \mu \mathrm{M}$ (Fig 3f). These results suggest that $N$. caninum-induced NLRP3 inflammasome activation was upregulated by the ROS inducer PG.

To investigate whether PG-regulated NLRP3 inflammasome activation also plays a role in eliminating $N$. caninum in PMs, N. caninum-infected PMs were treated with or without PG, parasites in parasitophorous vacuoles of $N$. caninum-infected PMs were quantified by confocal microscopy. The results showed that the percentage of $N$. caninum infected cells was decreased in the PG-treated group in a dose-dependent manner $\left(F_{(2,6)}=\right.$ 226.99, $P<0.0001$; Fig. $3 g$ ), and the parasite number in parasitophorous vacuoles of PMs was also decreased in the PG-treated group compared with the infection-only group $\left(F_{(2,6)}=230.48, P<0.0001\right.$; Fig. 3 h). Meanwhile, the number of $N$. caninum in PMs was further assessed by qPCR, and the parasite burden in PMs was indeed significantly decreased in the PG-treated group in a dosedependent manner $\left(F_{(2,6)}=55.721, P<0.0001\right.$; Fig. 3i). These results indicate that PG can inhibit the replication of N. caninum in PMs.

\section{NLRP3 deletion blocked ROS-mediated inflammasome activation in $N$. caninum-infected PMs}

To explore whether NLRP3 is one of the primary factors underlying ROS-mediated inflammasome activation, we studied the effects of the ROS inhibitor NAC and the ROS inducer PG on inflammasome activation in $\mathrm{Nlrp}^{-/-}$PMs. We found that the intracellular ROS was increased by PG or attenuated by NAC in N. caninuminfected WT and Nlrp3 ${ }^{-/-}$PMs (WT: $F_{(3,8)}=29.07, P$ $=0.0001 ;$ Nlrp3 $^{-/-}: F_{(3,8)}=114.732, P<0.0001$; Fig. 4a). NLRP3 was essential for $N$. caninum-induced IL-1 $\beta$ 


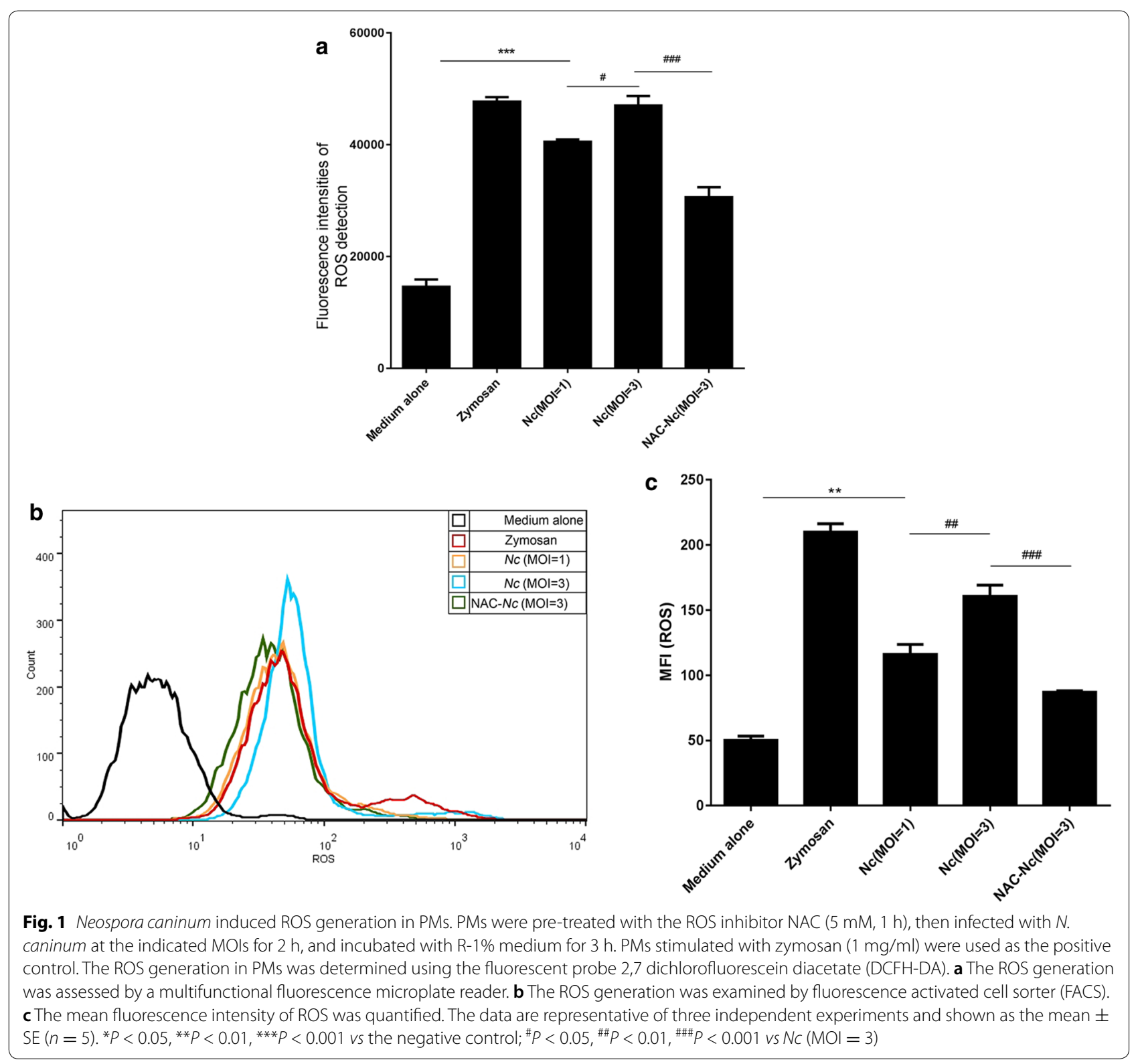

(See figure on next page.)

Fig. 2 Roles of the inhibitor NAC in regulating NLRP3 inflammasome and parasite proliferation during N. caninum infection. PMs were pre-treated with or without NAC (5 mM; 1 h) and infected with N. caninum (MOl of 3:1 or 1:1, parasite: cell; $8 \mathrm{~h}$ ). ATP (5 mM; $30 \mathrm{~min})$ added to the N. caninum-infected cells was used as a positive control. At $24 \mathrm{~h}$ post-infection, the cell lysates and supernatants were collected. a Cell death was monitored by measuring LDH release in supernatants. b NLRP3 expression and active IL-1 $\beta$ ( $p 17$ ) was assessed by western blotting. $\mathbf{c} I L-1 \beta$ production in supernatants was measured by ELISA. PMs were pre-treated with or without NAC $(5 \mathrm{mM} ; 1 \mathrm{~h})$ and then infected with $N$. caninum at a $\mathrm{MOl}$ of 1 for $4 \mathrm{~h}$. At $24 \mathrm{~h}$ post-infection, the cells were collected. $\mathbf{d}$ Percentage of $\mathrm{N}$. caninum infected cells was counted by fluorescence confocal microscopy. e Quantification of parasites in parasitophorous vacuoles were monitored by fluorescence confocal microscopy. $\mathbf{f}$ Number of $N$. caninum in infected PMs was assessed by quantitative PCR. The data are shown as the mean \pm SE from three independent experiments. ${ }^{*} P<0.05$, ${ }^{* *} P<0.01$, and ${ }^{* * *} P<0.001$ vs the NAC group 


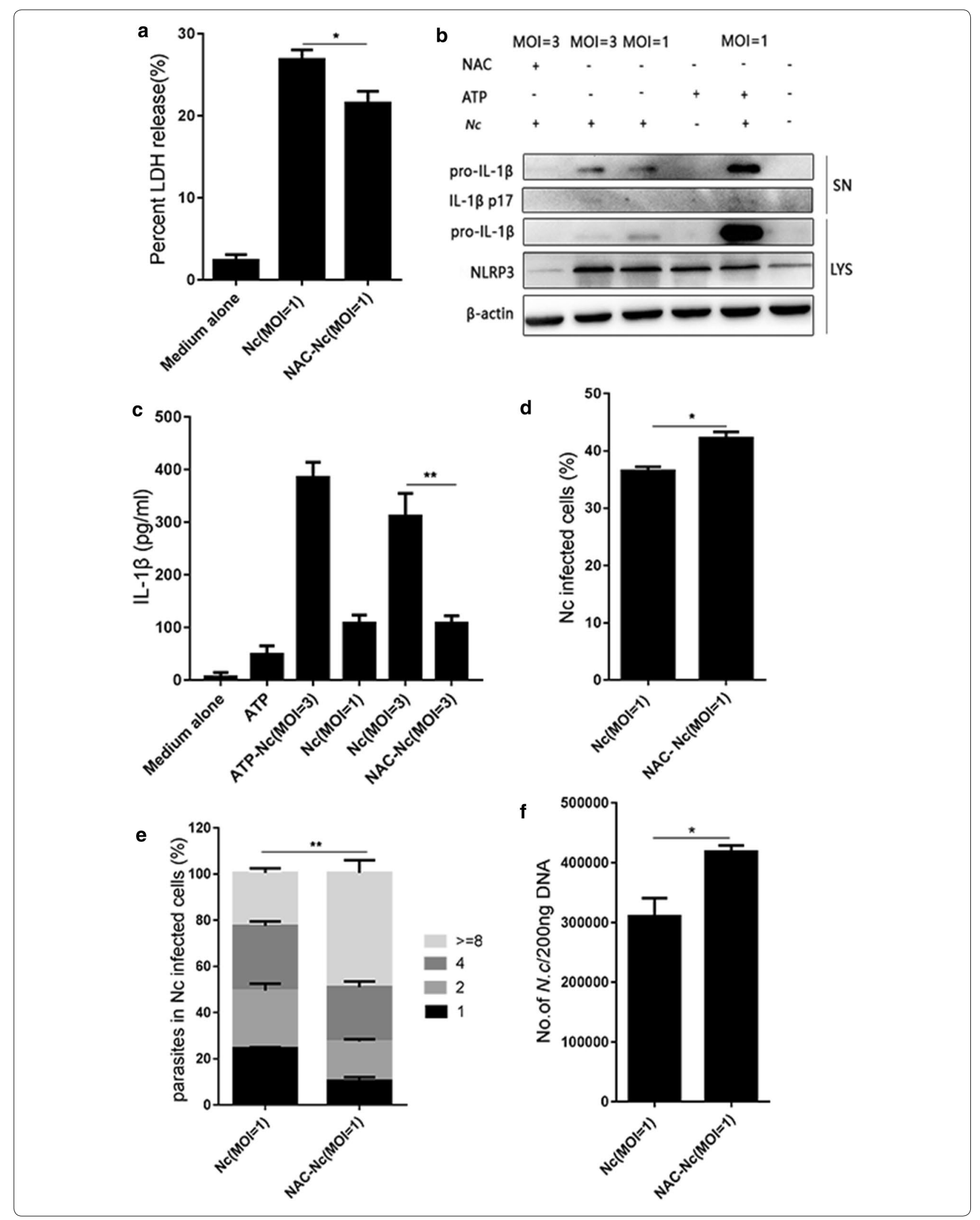


secretion [36]. We found that NLRP3 expression in cell lysates and active IL- $1 \beta$ secretion in supernatants of $N$. caninum-infected WT PMs were greatly increased by PG treatment. In contrast, NAC significantly decreased NLRP3 expression and active IL-1 $\beta$ production in WT PMs (active IL-1 $\beta$ : WT: $F_{(5,12)}=929.66, P<0.0001$; $N \operatorname{lrp} 3^{-/-}: F_{(5,12)}=263.71, P<0.0001$ ) (Fig. 4b, c). However, compared with the WT group, active IL-1 $\beta$ production was inhibited in $\mathrm{Nlrp}^{-/-} \mathrm{N}$. caninum-infected PMs, and NAC or PG treatment also failed to alter active IL-1 $\beta$ secretion in $\mathrm{Nlrp}^{-/-}$PMs (Fig. 4b, c). These results indicate that ROS depends on NLRP3 to activate the inflammasome in $N$. caninum-infected PMs.

To further explore whether $N$. caninum induced NADPH-dependent ROS production to mediate NLRP3 inflammasome activation, PMs were pre-treated with the NADPH oxidase inhibitor DPI. Similar with NAC, the intracellular ROS was markedly attenuated by DPI in $N$. caninum-infected WT and Nlrp ${ }^{-/-}$PMs (WT: $F_{(3,8)}=$ 11.92, $P=0.0030$; Nlrp3 ${ }^{-/-}: F_{(3,8)}=42.45, P<0.0001$; Fig. $4 d)$. Expectedly, active IL-1 $\beta$ production was also significantly decreased by DPI in $N$. caninum-infected WT PMs. Upon knockout of NLRP3, DPI did not alter the IL- $1 \beta$ secretion of $N$. caninum infected PMs compare to the infection-only PMs (WT: $F_{(3,8)}=82.94, P<$ $0.0001 ; \operatorname{Nlrp}^{-/-}: F_{(3,8)}=1.265, P=0.3500$; Fig. 4e). In addition, we detected the influences of NAC, DPI and PG on the LDH release in N. caninum infected PMs. The results found that inducer PG significantly increased the LDH release in $N$. caninum infected WT PMs, but LDH release was greatly reduced by inhibitors NAC and DPI. As expected, NAC and PG did not influence the LDH release in the Nlrp $3^{-/} N$. caninum infected PMs (WT:

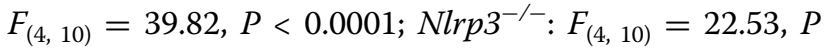
$<0.0001$; Fig. 4f). The release of ROS, IL-1 $\beta$, and LDH in DPI-pre-treated WT PMs were lower than that in NAC pre-treatment. These phenomena further suggest that NADPH-dependent ROS is an upstream signal that activates NLRP3 inflammasome during N. caninum infection.

\section{PG resisted $N$. caninum infection by regulating NLRP3 inflammasome pathway}

To evaluate the influence of ROS-mediated NLRP3dependent inflammasome on the parasite burden, $N$. caninum-infected WT PMs or Nlrp3 $3^{-/-}$PMs were pretreated with the ROS inhibitor NAC or treated with the ROS inducer PG. The results showed that the more $N$. caninum infected cells and parasite burdens in $N l r p 3^{-/-}$ PMs were observed than in WT PMs (Fig. 5a). The percentage of $N$. caninum infected WT PMs (based on confocal microscopy) was significantly decreased by PG treatment, but greatly increased by NAC pre-treatment compared with the infection-only WT PMs. In contrast, no significant difference in the percentage of $N$. caninum infected cells was found between NAC pre-treated $\mathrm{Nlrp}^{-/-} \mathrm{PMs}$ and the infection-only Nlrp3 ${ }^{-/-} \mathrm{PMs}$, though PG did cause a slight decrease in Nlrp $3^{-/-}$PMs (WT: $F_{(2,6)}=94.42, P<0.0001 ; \mathrm{Nlrp3}^{-/-}: F_{(2,6)}=48.37$, $P=0.0002$; Fig. 5b). To further determine the effects of the NAC and the PG on the parasite burden of $\mathrm{Nlrp3}^{-/-}$ PMs, we counted the parasite number in parasitophorous vacuoles of $\mathrm{Nlrp3}^{-/-}$PMs using confocal microscopy and analyzed the number of $\mathrm{N}$. caninum in $N \mathrm{Nrp3} 3^{-/-} \mathrm{PMs}$ by qPCR. The results showed that there was no significant difference in parasite burdens between the NAC-pretreated and infection-only groups, but the PG-treated group exhibited a slight decrease in parasite burden (Fig. 5 c: $F_{(2,6)}=58.83, P=0.0001$; Fig. 5 d: $F_{(2,6)}=9.765$, $P=0.0130)$. These results show that ROS-mediated NLRP3-dependent inflammasome activation plays a key role in controlling $N$. caninum infection, and the PG can inhibit parasite replication in $N$. caninum-infected PMs mainly by promoting NLRP3 inflammasome activation and other mechanism.

To further explore the role of PG-induced NLRP3 inflammasome activation in inhibiting $N$. caninum

\footnotetext{
(See figure on next page.)

Fig. 3 PG inhibited N. caninum replication by increasing NLRP3 inflammasome activation in vitro. PMs were treated with PG at various concentrations (15, 30, 60 and $80 \mu \mathrm{M})$ for 24 or $48 \mathrm{~h}$. a The cell viability of PMs was determined by CCK-8 assays. b PMs were treated with PG (15 or 30 or $60 \mu \mathrm{M}$ ) for $3 \mathrm{~h}$, PMs stimulated with zymosan ( $1 \mathrm{mg} / \mathrm{ml} ; 1 \mathrm{~h}$ ) was used as positive controls, ROS production in PMs was assessed using a multifunctional fluorometric reader. PMs were infected with $N$. caninum at the indicated MOls for $2 \mathrm{~h}$, and incubated with or without PG for $3 \mathrm{~h}$. c ROS production was detected by a multifunctional fluorometric reader. PMs were infected with $\mathrm{N}$. caninum at the indicated MOls for $8 \mathrm{~h}$, then incubated with or without PG. At $36 \mathrm{~h}$ post-infection, $\mathbf{d}$ cell death was monitored by measuring LDH activity in the supernatants, $\mathbf{e} I L-1 \beta$ in supernatants was measured using ELISA, f NLRP3, IL-1 $\beta$ (p17) and caspase-1 (p20) were monitored by western blotting. PMs were infected with $N$. caninum at the indicated MOls for $4 \mathrm{~h}$, then incubated with or without PG. At $24 \mathrm{~h}$ post-infection, percentage of $\mathrm{N}$. caninum infected cells (g) and quantification of parasites (h) in parasitophorous vacuoles were monitored by fluorescence microscopy. $\mathbf{i}$ Number of $N$. caninum in infected PMs was determined by $q P C R$. The data are shown as the mean \pm SE from three independent experiments. ${ }^{*} P<0.05,{ }^{* *} P<0.01$, ${ }^{* * *} P<0.001$ vs the

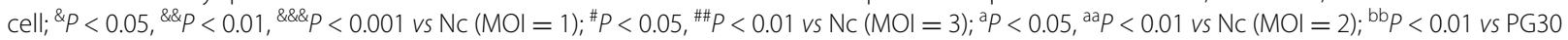
$\mu \mathrm{M}-\mathrm{Nc}(\mathrm{MOI}=1)$
} 

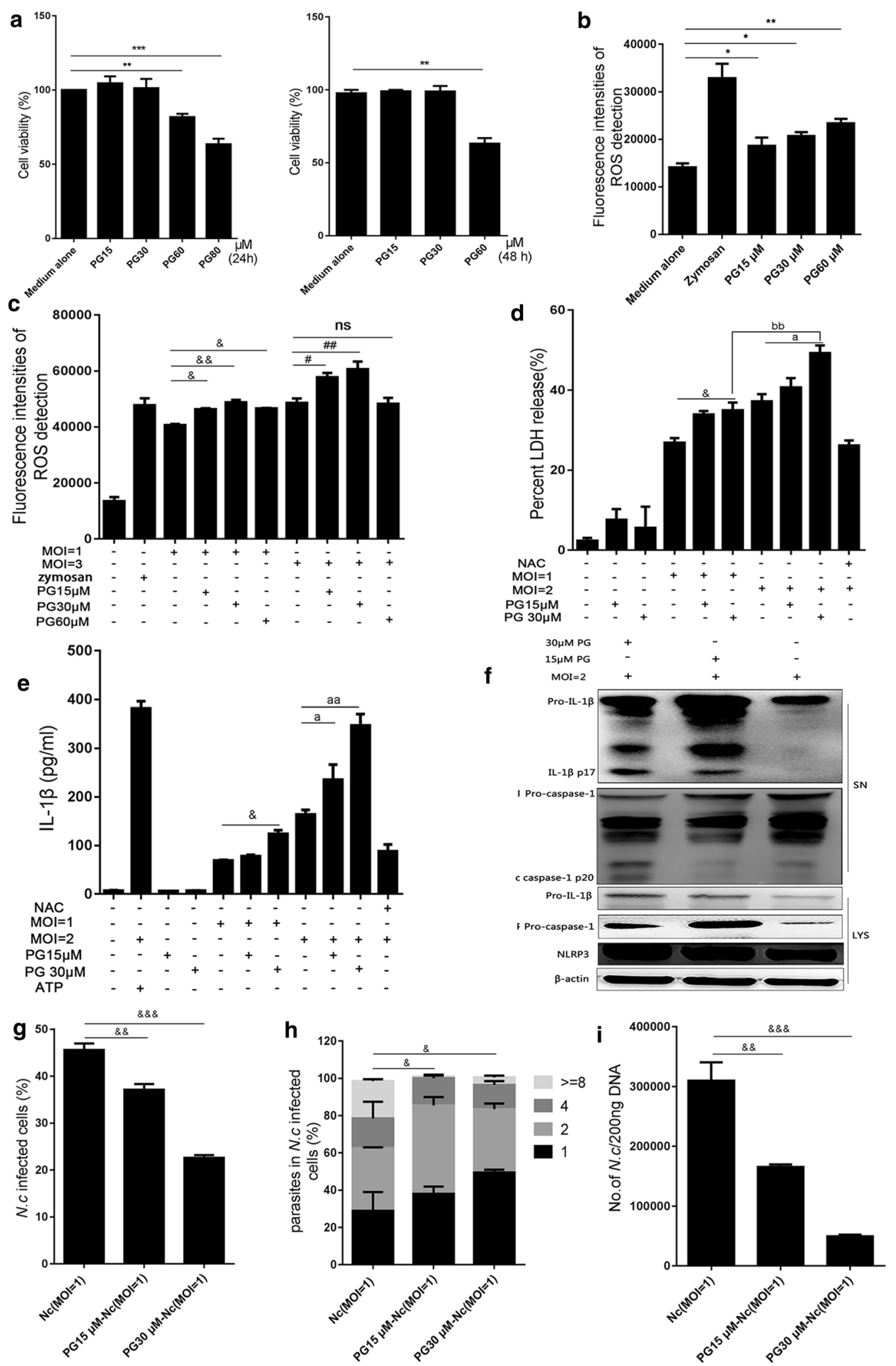
(See figure on next page.)

Fig. 4 NLRP3 deletion blocked ROS-induced inflammasome activation during N. caninum infection in vitro. WT and N/rp3 $3^{-/-}$PMs were pre-treated with or without the ROS inhibitor NAC ( $5 \mathrm{mM}, 1 \mathrm{~h}$ ), then infected with $\mathrm{N}$. caninum at an $\mathrm{MOl}$ of 1 for $2 \mathrm{~h}$, infected PMs were incubated with or without PG at post infection for $3 \mathrm{~h}$. a ROS production was assessed using a multifunctional fluorometric reader. WT and N/rp3 $3^{-1-}$ PMs were pre-treated with or without the ROS inhibitor NAC ( $5 \mathrm{mM}, 1$ h), then infected with $\mathrm{N}$. caninum at an $\mathrm{MOI}$ of 2 for $8 \mathrm{~h}$, and incubated with or without PG. ATP (5 mM; $30 \mathrm{~min}$ ) added to the $N$. caninum-infected cells was used as a positive control. At $36 \mathrm{~h}$ post-infection, IL-1 $\beta$ in supernatants was detected by ELISA (b), IL-1 $\beta$ (p17) and NLRP3 expression were detected by western blotting (c). WT and N/rp3 ${ }^{-1-}$ PMs were pre-treated with or

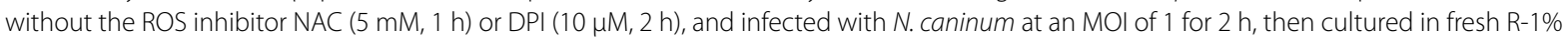
medium for $3 \mathrm{~h}$, ROS production was assessed using a multifunctional fluorometric reader (d); or infected with N. caninum at the indicated $\mathrm{MOls}$ for $8 \mathrm{~h}$, and incubated with or without PG, at $36 \mathrm{~h}$ post-infection, IL-1 $\beta$ in supernatants was detected by ELISA (e). f Percent LDH release is measured by the LDH assay kit. The data are shown as the mean \pm SE from three independent experiments. ${ }^{*} P<0.05,{ }^{* *} P<0.01,{ }^{* * *} P<0.001$ vs the Nc group in WT PMs or N/rp3 $3^{-1-} \mathrm{PMs}^{;}{ }^{\# \#} \mathrm{P}<0.001$ vs PG30-Nc $(\mathrm{MOI}=2)$ in N/rp3 $3^{-/-} \mathrm{PMs}$

infection in vivo, WT and $N l r p 3^{-/-}$mice were infected with $N$. caninum and then treated with PG. Inflammasome-mediated IL-18 secretion in serum and parasite burdens in peritoneal exudate cells were measured. The results showed that serum IL-18 in PG-treated WT mice was obviously higher than in infection-only WT mice, but there was no significant difference in IL-18 production between $N$. caninum-infected $\mathrm{Nlrp}^{-/-}$mice with or without PG treatment, and IL-18 production in $N l r p 3^{-1-}$ mice induced by PG treatment was lower than the production in the corresponding WT mice (WT: $F_{(2,}$ ${ }_{12)}=76.96, P<0.0001$; $\operatorname{Nlrp}^{-/-}: F_{(2,12)}=0.615, P=$ 0.5566; Fig. 5e). After PG treatment, parasite burdens in peritoneal exudate cells in WT mice were significantly decreased. In addition, parasite burdens in peritoneal exudate cells of $\mathrm{Nlrp}^{-/-}$mice was significantly increased than in WT mice. With PG treatment the parasite burden was greatly decreased in both WT and Nlrp $3^{-/-}$mice, and PG treatment had a more significant inhibiting effect on WT mice than in $N$ lrp $3^{-/-}$mice (WT: $t_{(4)}=11.26$, $P=0.0004$; lrp3 $^{-1-}: t_{(4)}=8.416, P=0.0011$; Fig. 5f). These results further confirm the findings of the in vitro experiments that the effects of PG on regulating NLRP3 inflammasome activation and indicate that PG plays a vital role in controlling $N$. caninum infection in both NLRP3 dependent manner and other mechanism in vivo.

\section{Roles of the PG in controlling $N$. caninum proliferation and protecting host}

To further investigate whether the ROS-NLRP3 axis could be a candidate pathway to identify drugs for the treatment of neosporosis and explore the effects of PG on $N$. caninum-infected mice. The WT mice were intraperitoneally injected with or without $2.5 \times 10^{7} \mathrm{~N}$. caninum tachyzoites, then $N$. caninum-infected mice were intraperitoneally injected with or without PG. Weight, survival time, parasite burdens and pathological changes in tissues were monitored. The results showed that the weight loss caused by $N$. caninum infection was decreased in PG group compared with the infection-only group (Fig. 6a). In addition, the infection-only group had a lower survival rate, and none of the mice survived after the ninth day post-infection. However, PG treatment can greatly increase the survival rate of infected mice when compare with the infection-only group $\left(t_{(4)}=6.047, P=\right.$ 0.0038; Fig. 6b).

To investigate the roles of PG in controlling parasite replication and dissemination in tissues, samples from the heart, the liver, the spleen, the lung, the kidney and the brain of mice were collected to assess parasite burdens and histopathological changes. Parasite burdens in these tissues were significantly decreased in the PGtreated group compared with the infection-only group on day 8 pi (heart: $t_{(4)}=3.031, P=0.0387$; liver: $t_{(4)}=7.801$, $P=0.0015$; spleen: $t_{(4)}=28.65, P<0.0001$; lung: $t_{(4)}=$ 6.502, $P=0.0029$; kidney: $t_{(4)}=16.22, P<0.0001$; and brain: $t_{(4)}=5.589, P=0.0050$; Fig. $\left.6 \mathrm{c}-(\mathrm{i})\right)$. Histopathological examination showed that heart, liver, spleen, lung, kidney, and brain tissues from the infection-only group had severe inflammatory responses with hemorrhage, vascular phenomena, leukocyte margination, interstitial thickening, and necrotic foci when compared to that in PBS group. These findings included hemorrhagic symptoms in the heart tissues, degenerative changes, and necrosis in liver tissues. Hemorrhage and erythrocytes in the spleen white pulp were increased, while the damage to the heart, liver and spleen were considerably mitigated in the PG treatment group, and only a small amount of damage was observed in the liver and spleen. Alveolar wall thickening, neutrophil infiltration, and alveolar hemorrhage were exhibited in the lungs in the infectiononly group, whereas only slight pathological symptoms were observed in the PG-treated group. The brain in infected mice showed degeneration and necrosis of neurons, severe meningitis, and severe perivascular inflammation, whereas milder histopathological changes were observed in brains of the PG-treated mice (Fig. 6c-(ii)). Taken together, these results indicate that PG has significant protecting effects on the host by decreasing the death rate, weight loss, parasite burdens in tissues and 

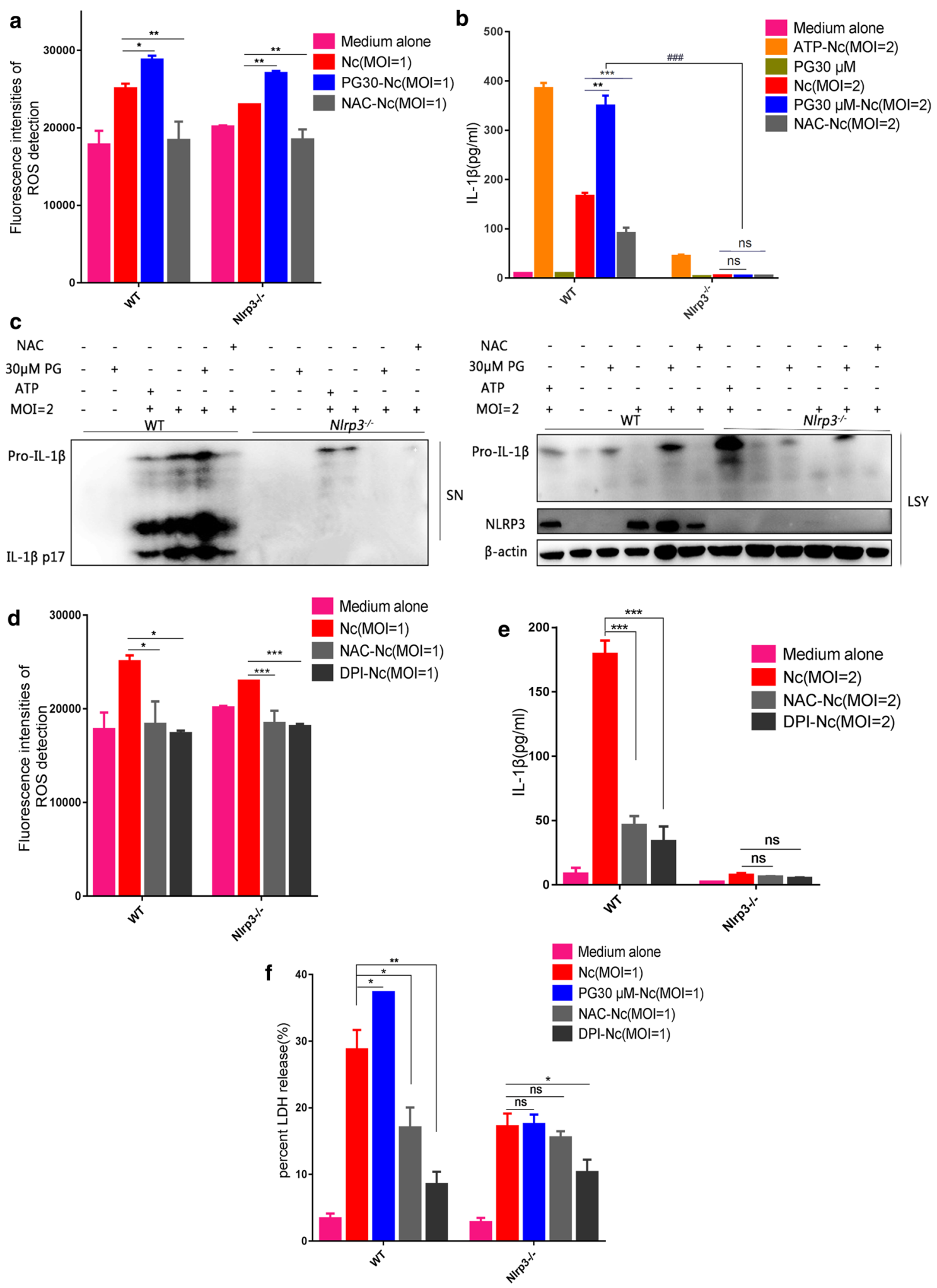

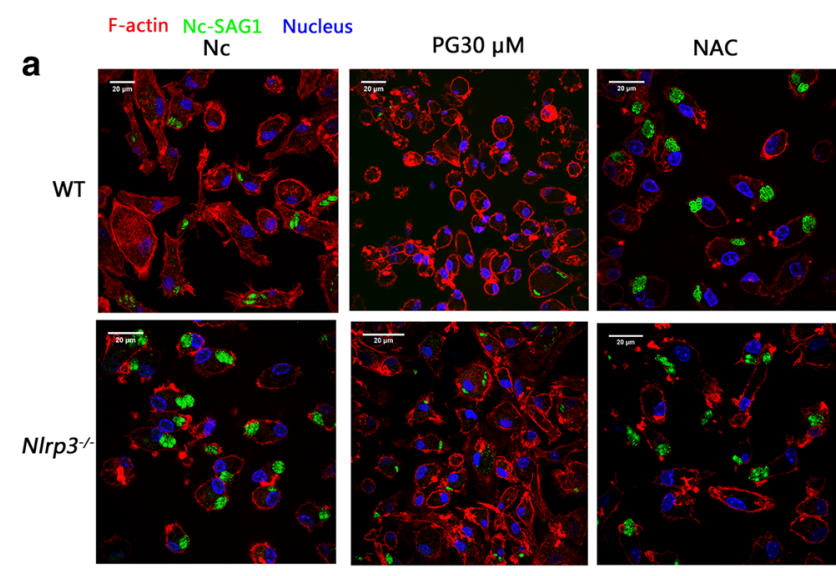

\section{b}
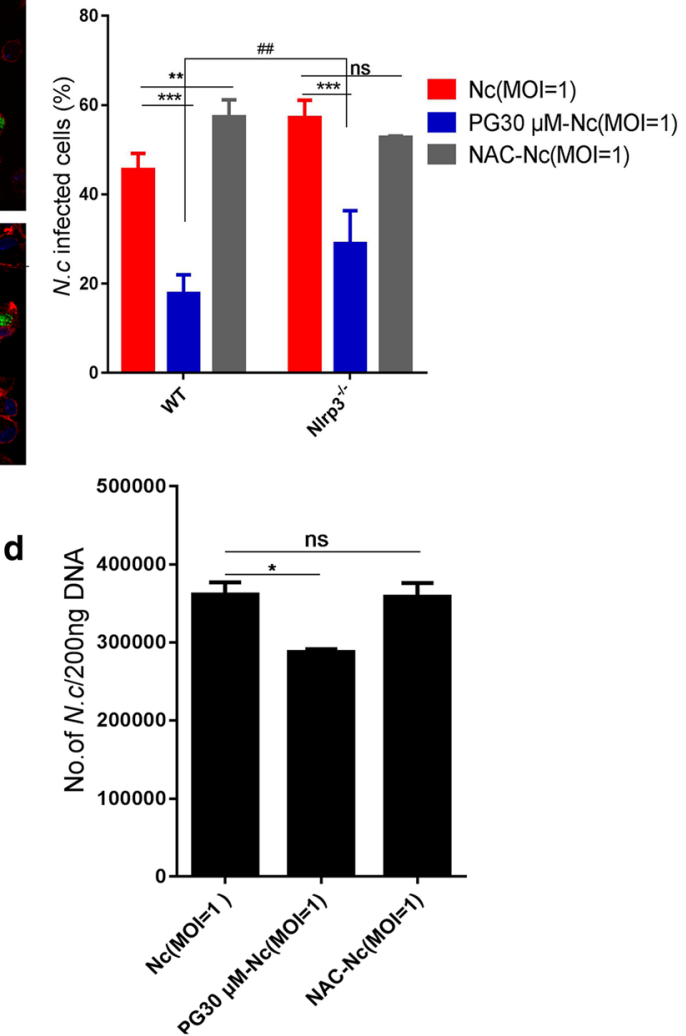

e

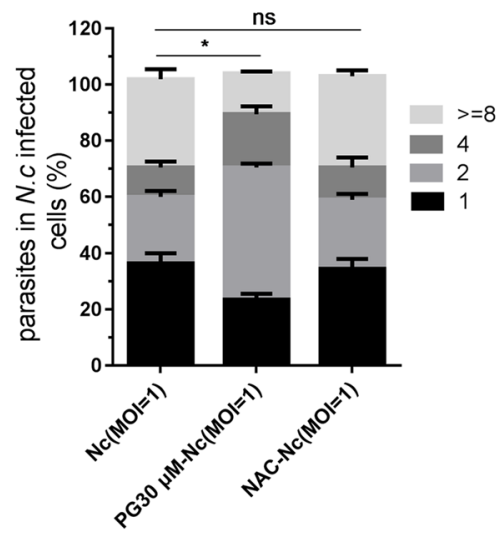

- PBS

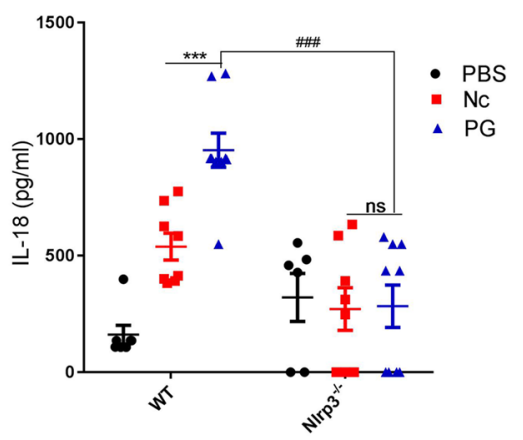

f

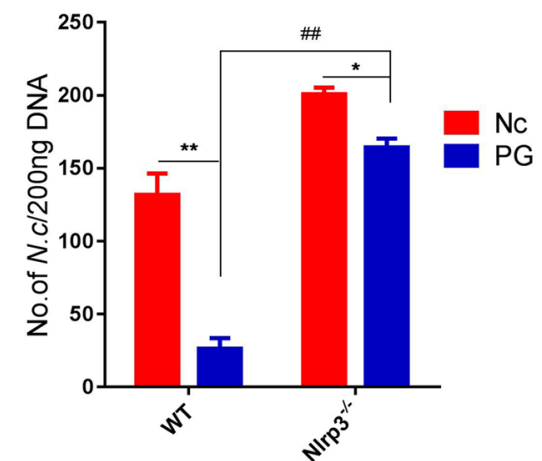

Fig. 5 PG regulated ROS-NLRP3 pathway in resisting N. caninum infection. WT and N/rp3 $3^{-1-}$ PMs were pre-treated with or without NAC (5 mM, $1 \mathrm{~h}$ ), then infected with $N$. caninum an $\mathrm{MOI}$ of 1 for $4 \mathrm{~h}$, and $N$. caninum-infected PMs were incubated with or without PG (30 $\mu \mathrm{M})$. The PMs were collected at $24 \mathrm{~h}$ post-infection. a PMs were stained with polyclonal antiserum against NcSAG1, which reacts with $N$. caninum tachyzoites. The F-actin was labeled with TRITC-phalloidin and the nuclei was stained with DAPI for confocal microscopy observation. $\mathbf{b}$ Percentage of $\mathrm{N}$. caninum infected cells was monitored by fluorescence microscopy. c Quantification of parasites in vacuoles in N/rp3 $3^{-1}$ PMs were monitored by fluorescence microscopy. $\mathbf{d}$ Number of parasites in N/rp3 $3^{-/}$PMs were detected by quantitative PCR. WT and N/rp3 $3^{-/}$mice were intraperitoneally infected with $2.5 \times 10^{7} \mathrm{~N}$. caninum tachyzoites or PBS (0.5 ml). After 2 days, the infected groups were injected with PG (75 mg/kg, in $0.5 \mathrm{ml}$ PBS) or PBS (0.5 ml). Serum and peritoneal exudate cells were collected at day 8 . e IL-18 in serum was measured by ELISA. f Parasite burdens in peritoneal exudate cells was detected by quantitative PCR. The data are shown as the mean \pm SE from three independent experiments. ${ }^{*} P<0.05$, ${ }^{* *} P<0.01$, ${ }^{* * *} P<0.001$ vs the Nc group in WT PMs or NIrp3 ${ }^{-/-}$PMs; ${ }^{\# \#} P<0.01,{ }^{\# \#} P<0.001$ vs PG30-Nc $(\mathrm{MOI}=2)$ in N/rp3 ${ }^{-1-}$ PMs 
the tissue lesions. These indicate that ROS inducer PG could be a potential drug for treating neosporosis and the ROS-mediated NLRP3 pathway could be used to identify further candidate drugs for the treatment of neosporosis.

\section{Discussion}

Neospora caninum can invade and replicate in PMs and induce immune responses [8]. The innate immune response plays a key role in controlling pathogen infection, and mediates an appropriate adaptive immune response to promote and strengthen the elimination of invasive parasites, as well as build immunological memory to protect against reinfection [37]. IL-1 $\beta$ is a marker of NLRP3 inflammasome activation and essential for cell defense in response to parasite infection. Previous studies have reported that $N$. caninum infection can induce cleavage of caspase- 1 and IL- $1 \beta$ secretion in PMs [8] and bone marrow-derived macrophages [36] and bovine macrophages [38], However, the molecular mechanism of $N$. caninum-induced NLRP3 inflammasome activation was still unclear. In this study, we demonstrate that NLRP3 inflammasome activation is triggered by N. caninum-induced ROS production, and the ROS inducer PG controls $N$. caninum infection mainly by regulating NLRP3-dependent inflammasome activation in vitro and in vivo.

NLRP3 inflammasome activation requires two signals. The first signal is provided by the activation of nuclear factor NF- $\mathrm{kB}$, which upregulates NLRP3, pro-IL-1 $\beta$ and pro-IL-18. The second signal is provided by various DAMPs or PAMPs, and leads to the formation of inflammasome complex [39, 40]. The second signal stimuli include numerous pathogens such as bacteria, viruses, fungi, and their components, ATP, pore-forming toxins, and particulate crystals and aggregates [41-43]. ROS generation is regarded as one of the molecular mechanisms underlying NLRP3 inflammasome activation [19]. ROS production is one of the most important factors for various biological functions, including proliferation, differentiation, immune response and cell survival [44]. Currently, ROS-induced NLRP3 inflammasome activation remains controversial [45]. Many studies have reported that the NLRP3 inflammasome in Trypanosoma cruzi-infected macrophages is inhibited by the inhibition of ROS [22], but Bortolucci's group demonstrated that Trypanosoma cruzi-induced NLRP3 activation is independent on ROS generation [13]. Leishmania donovanimediated ROS generation inhibits NLRP3 inflammasome activation in RAW 264.7 cells [46]. These differences in ROS-mediated NLRP3 inflammasome activation differ among the protozoan parasites or cell types. Therefore, it is necessary to explore ROS-mediated NLRP3 inflammasome activation in $N$. caninum-infected PMs. In the present study, we found that ROS generation and NLRP3 inflammasome activation were induced in dose-dependent manners by $N$. caninum infection in PMs.

ROS production is related to the occurrence of respiratory burst in macrophages, it is a process that depends on $\mathrm{NADPH}$ oxidase activation to promote the rapid increase of superoxide free radicals and $\mathrm{H}_{2} \mathrm{O}_{2}$ in early recognition of pathogens [47]. Cell death and expressions of NLRP3, caspase- 1 and IL- $1 \beta$ induced by nicotine in endothelial cells were decreased by NAC pretreatment [48]. IL-1 $\beta$ secretion in THP1 cells was diminished by the NADPH oxidase inhibitor DPI and the ROS inhibitor NAC [27]. In our study, similar results were observed in NAC or DPI pre-treated WT PMs, $N$. caninum-induced releases of ROS, IL- $1 \beta$ and LDH were significantly decreased in both DPI group and NAC group. These results indicate that $N$. caninum-induced NADPH oxidase-dependent ROS generation triggers NLRP3 inflammasome activation in PMs. The ROS inhibitors also have various side effects, but they are still effective in demonstrating the effects of ROS on NLRP3 inflammasome [20]. And whether mitochondrial ROS is responsible for NLRP3 inflammasome activation during $N$. caninum infection needs further study. IL-1 $\beta$ secretion was induced in $N$. caninum-infected PMs, at the MOI of 3 for $24 \mathrm{~h}$, and $N$. caninum infection of PMs induced significant IL-1 $\beta$ secretion in time- and dose-dependent manners [8], IL-1 $\beta$ secretion of PMs infected with $N$. caninum at an MOI of 3 for $24 \mathrm{~h}$ was lower. But the cell death of PMs infected with $N$. caninum at an MOI of 3 for $36 \mathrm{~h}$ was greatly higher (data not shown), so we chose an MOI of 2 for $36 \mathrm{~h}$ to establish the $N$. caninum infection model of PMs in activating NLRP3 inflammasome, and an MOI of 1 for $24 \mathrm{~h}$ to establish the $N$. caninum infection model of PMs in monitoring parasite burdens. A previous study

(See figure on next page.)

Fig. 6 Roles of the PG in controlling N. caninum proliferation and protecting host. WT mice were intraperitoneally infected with $2.5 \times 10^{7} \mathrm{~N}$. caninum tachyzoites or PBS ( $0.5 \mathrm{ml})$ for 2 days and then the infected groups were injected with PG (75 mg/kg, in $0.5 \mathrm{ml}$ PBS) or PBS (0.5 ml). Each group of mice were monitored daily. a Weight change in mice was recorded for 7 days. b Survival of mice was monitored for 30 days. $\mathbf{c}(\mathrm{i})$ Parasite burdens were measured by quantitative PCR of total DNA (500 ng). c(ii) Histopathological analysis of heart, liver, spleen, lung, kidney and brain tissues of WT mice were conducted with H\&E staining at day 8 post-infection. Heart, liver, spleen, lung, and kidney tissues were examined at a magnification of $100 x$, and the brain tissue was examined at a magnification of $400 x$. The data are shown as the mean $\pm S E$ from three independent experiments. ${ }^{*} P<0.05,{ }^{* *} P<0.01,{ }^{* * *} P<0.001$ vs the Nc group 


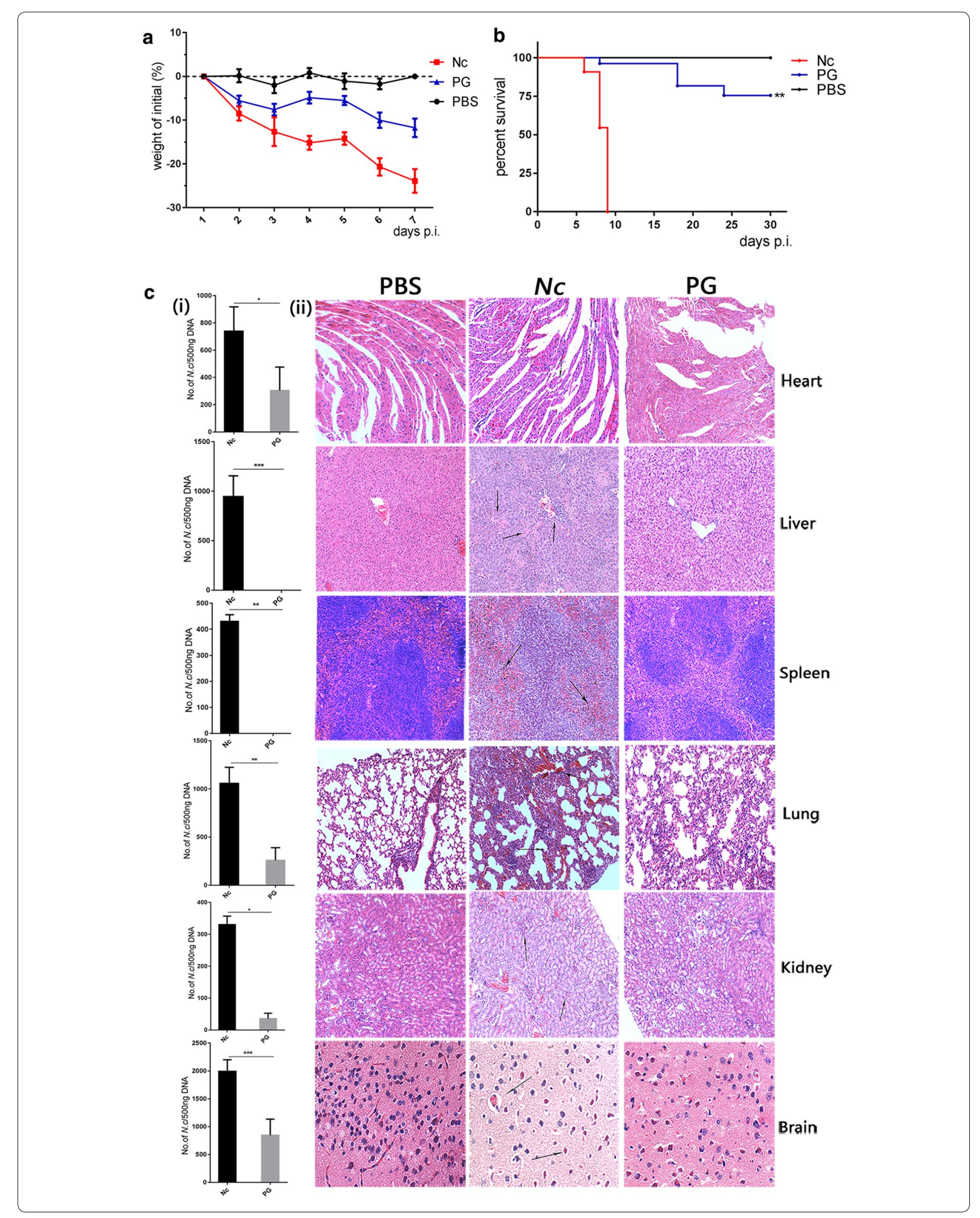


has found that $N$. caninum-induced inflammasome activation is mainly dependent on NLRP3 [36]. In this study, ROS generations induced by PG or attenuated by NAC or DPI, which did not completely alter the inflammasome activities in $N$. caninum-infected $N l r p 3^{-/-}$PMs. This indicates that ROS-mediated inflammasome activation mainly depends on NLRP3 during $N$. caninum infection. Interestingly, DPI still inhibited LDH release in $N \mathrm{Nrp}^{-/-}$ cells, probably by other mechanisms [30]. Additionally, ROS-NLRP3 inflammasome activity was observed in $N$. caninum-infected mice. These results suggest that ROS depends on NLRP3 to activate the inflammasome during $N$. caninum infection in vitro and in vivo, and ROS is an activator of $N$. caninum-induced NLRP3 inflammasome.

The NLRP3 inflammasome plays an essential role in controlling pathogenic microbial infections $[8,49]$. Toxoplasma gondii-induced NLRP3 inflammasome activation inhibits parasite proliferation in macrophages and human small intestinal epithelial cells [50, 51]. Neospora caninum-induced NLRP3 inflammasome activation is beneficial for parasites elimination in PMs and mice $[8,36]$. Neospora caninum can induce NF- $\mathrm{kB}$ activation [11], this signal was used as a first signal, and ROS inducer PG was applied as a second signal to enhance NLRP3 inflammasome activation in this study. Weight loss, mortality and histopathological lesions are increased in $N$. caninuminfected WT mice [36, 52], these are important data to assess N. caninum infection in mice. We chose $75 \mathrm{mg} /$ $\mathrm{kg}$ PG for the in vivo study, because this dose is relatively safe for mice [32, 33]. Here, we found that PG had a good effect on decreasing mortality and weight loss, and the parasite burden in tissues was also significantly decreased after PG treatment when compared with the infectiononly WT mice. In addition, histopathological lesions were also alleviated in the PG-treated group, similar to the effect of licochalcone A that induces ROS generation to combat T. gondii in vivo [53], and kojic acid promotes superoxide anion $\left(\mathrm{O}_{2}^{*}\right)$ generation and exhibits significant direct and indirect anti-Toxoplasma activity [54]. Previous studies only reported that PG inhibits cancer cell growth [55-57] and enhances cell death by increasing $\mathrm{O}_{2}^{-}$ levels $[58,59]$. To the best of our knowledge, our study is the first to indicate that ROS inducer PG promotes NLRP3-dependent inflammasome activation to inhibit parasite proliferation in vivo and in vitro. In addition, PG also has a NLRP3-independent manner in controlling $N$. caninum infection, but the underlying mechanisms require further evidence [22, 60]. Taken together, ROS-mediated NLRP3 inflammasome activation could be a candidate pathway for identifying new drugs for the treatment of neosporosis, and PG may be a new drug for the treatment of neosporosis, but further research on PG in bovine species is still needed.

\section{Conclusions}

We demonstrate the relationships between ROS, the NLRP3 inflammasome, and N. caninum infection. Neospora caninum can induce NADPH-dependent ROS production in PMs, and ROS-mediated NLRP3 inflammasome activation participated in host response against $N$. caninum infection. Furthermore, we found that ROS inducer PG promoted NLRP3 inflammasome activation to increase host resistance during N. caninum infection. This study indicates that ROS-mediated NLRP3 inflammasome has implications for providing a new solution for the treatment of neosporosis in the future, and enriches our knowledge of the molecular mechanism for host innate immune response and host defense during $N$. caninum infection.

\section{Abbreviations}

BSA: bovine serum albumin; qPCR: quantitative polymerase chain reaction: ELISA: enzyme-linked immunosorbent assay; FBS: fetal bovine serum; CCK-8: cell counting kit-8; IL-1 $\beta$ : interleukin-1 $\beta$; DAPI: 4',6-diamidino-2-phenylindole; TRITC: tetramethylrhodamine isothiocyanate; SN: supernatants; LYS: cell lysates; LDH: lactate dehydrogenase; MOI: multiplicities of infection; PBS: phosphate buffer saline; PBST: phosphate-buffered saline with tween-20; PCR: polymerase chain reaction; SE: standard error of the mean.

\section{Acknowledgements}

The authors would like to thank Yue Taotao for assisting with the collection of tissues in vivo.

\section{Authors' contributions}

$\mathrm{LL}, \mathrm{XW}$ and $X C Z$ designed and conceived the experiments. $L L, P G, X Z, S L$ and $S X L$ carried out the experiments. $L L, X W, J L, N Z, X L$ and $X X Z$ performed the data analysis. $L L, X W$ drafted and $W L$ revised the manuscript. All authors read and approved the final manuscript.

\section{Funding}

Project support was provided by the National Natural Science Foundation of China (Grant No. 31902296), National Key Basic Research Program (973 program) of China (Grant No. 2015 CB 150300) and China Postdoctoral Science Foundation (Grant No. 2019M661217).

Availability of data and materials

All data generated or analyzed during the present study are included in this published article.

\section{Ethics approval and consent to participate}

The procedures for the care and use of animals were in accordance with the guidelines of the Institutional Animal Care and Use Committee of Jilin University (IACUC permit no. 201711035).

\section{Consent for publication}

Not applicable.

\section{Competing interests}

The authors declare that they have no competing interests.

\section{Author details \\ ${ }^{1}$ Key Laboratory of Zoonosis Research, Ministry of Education, College of Vet- erinary Medicine, Jilin University, Changchun 130062, PR China. ${ }^{2}$ Heilongji- ang Key Laboratory for Zoonosis, College of Veterinary Medicine, Northeast Agricultural University, Harbin 150030, PR China.}

Received: 3 March 2020 Accepted: 30 August 2020

Published online: 05 September 2020 


\section{References}

1. Almeria S, Serrano-Perez B, Lopez-Gatius F. Immune response in bovine neosporosis: protection or contribution to the pathogenesis of abortion. Microb Pathog. 2017;109:177-82.

2. Dubey JP, Schares G, Ortega-Mora LM. Epidemiology and control of neosporosis and Neospora caninum. Clin Microbiol Rev. 2007;20:323-67.

3. Amdouni Y, Rjeibi MR, Awadi S, Rekik M, Gharbi M. First detection and molecular identification of Neospora caninum from naturally infected cattle and sheep in North Africa. Transbound Emerg Dis. 2018;65:976-82.

4. Reichel MP, Alejandra Ayanegui-Alcerreca M, Gondim LF, Ellis JT. What is the global economic impact of Neospora caninum in cattle - the billion dollar question. Int J Parasitol. 2013;43:133-42.

5. Marugan-Hernandez V. Neospora caninum and bovine neosporosis: current vaccine research. J Comp Pathol. 2017;157:193-200.

6. Sinnott FA, Monte LG, Collares TF, Silveira RM, Borsuk S. Review on the immunological and molecular diagnosis of neosporosis (years 2011-2016). Vet Parasitol. 2017;239:19-25.

7. Goodswen SJ, Kennedy PJ, Ellis JT. A review of the infection, genetics, and evolution of Neospora caninum: from the past to the present. Infect Genet Evol. 2013:13:133-50.

8. Wang X, Gong P, Zhang X, Wang J, Tai L, Wang X, et al. NLRP3 inflammasome activation in murine macrophages caused by Neospora caninum infection. Parasit Vectors. 2017;10:266.

9. Davoli-Ferreira M, Fonseca DM, Mota CM, Dias MS, Lima-Junior DS, da Silva MV, et al. Nucleotide-binding oligomerization domain-containing protein 2 prompts potent inflammatory stimuli during Neospora caninum infection. Sci Rep. 2016:6:29289.

10. Mineo TW, Benevides L, Silva NM, Silva JS. Myeloid differentiation factor 88 is required for resistance to Neospora caninum infection. Vet Res. 2009;40:32

11. Mineo TW, Oliveira CJ, Gutierrez FR, Silva JS. Recognition by toll-like receptor 2 induces antigen-presenting cell activation and Th1 programming during infection by Neospora caninum. Immunol Cell Biol. 2010;88:825-33.

12. Beiting DP, Peixoto L, Akopyants NS, Beverley SM, Wherry EJ, Christian DA, et al. Differential induction of TLR3-dependent innate immune signaling by closely related parasite species. PLoS One. 2014;9:e88398.

13. Zamboni DS, Lima-Junior DS. Inflammasomes in host response to protozoan parasites. Immunol Rev. 2015;265:156-71

14. De Torre-Minguela C, Mesa Del Castillo P, Pelegrin P. The NLRP3 and pyrin inflammasomes: implications in the pathophysiology of autoinflammatory diseases. Front Immunol. 2017;8:43.

15. Tschopp J, Schroder K. NLRP3 inflammasome activation: the convergence of multiple signalling pathways on ROS production? Nat Rev Immunol. 2010;10:210-5

16. Sharma D, Kanneganti TD. The cell biology of inflammasomes: mechanisms of inflammasome activation and regulation. J Cell Biol. 2016;213:617-29.

17. Schroder K, Zhou R, Tschopp J. The NLRP3 inflammasome: a sensor for metabolic danger? Science. 2010;327:296-300.

18. Latz E, Xiao TS, Stutz A. Activation and regulation of the inflammasomes, Nat Rev Immunol. 2013;13:397-411.

19. Dowling JK, O'Neill LA. Biochemical regulation of the inflammasome. Crit Rev Biochem Mol Biol. 2012;47:424-43.

20. Gross O, Thomas CJ, Guarda G, Tschopp J. The inflammasome: an integrated view. Immunol Rev. 2011;243:136-51.

21. Jaramillo M, Godbout M, Olivier M. Hemozoin induces macrophage chemokine expression through oxidative stress-dependent and -independent mechanisms. J Immunol. 2005;174:475-84.

22. Silva GK, Costa RS, Silveira TN, Caetano BC, Horta CV, Gutierrez FR, et al. Apoptosis-associated speck-like protein containing a caspase recruitment domain inflammasomes mediate IL-1 beta response and host resistance to Trypanosoma cruzi infection. J Immunol. 2013;191:3373-83.

23. Gov L, Schneider CA, Lima TS, Pandori W, Lodoen MB. NLRP3 and potassium efflux drive rapid IL-1 beta release from primary human monocytes during Toxoplasma gondii infection. J Immunol. 2017:199:2855-64.

24. Yamada J, Yoshimura S, Yamakawa H, Sawada M, Nakagawa M, Hara S, et al. Cell permeable ROS scavengers, Tiron and Tempol, rescue PC12 cell death caused by pyrogallol or hypoxia/reoxygenation. Neurosci Res. 2003:45:1-8.
25. Ray PD, Huang BW, Tsuji Y. Reactive oxygen species (ROS) homeostasis and redox regulation in cellular signaling. Cell Signal. 2012;24:981-90.

26. Wei Z, Hermosilla C, Taubert A, He X, Wang X, Gong P, et al. Canine neutrophil extracellular traps release induced by the apicomplexan parasite Neospora caninum in vitro. Front Immunol. 2016:7:436.

27. Dostert C, Petrilli V, Van Bruggen R, Steele C, Mossman BT, Tschopp J. Innate immune activation through Nalp3 inflammasome sensing of asbestos and silica. Science. 2008;320:674-7.

28. Rutkowski MR, McNamee LA, Harmsen AG. Neutrophils and inducible nitric-oxide synthase are critical for early resistance to the establishment of Tritrichomonas foetus infection. J Parasitol. 2007;93:562-74.

29. Li X, Zhang X, Gong P, Xia F, Li L, Yang Z, et al. TLR2(-/-) mice display decreased severity of giardiasis via enhanced proinflammatory cytokines production dependent on AKT signal pathway. Front Immunol. 2017:8:1186.

30. van de Veerdonk FL, Smeekens SP, Joosten LA, Kullberg BJ, Dinarello CA, van der Meer JW, et al. Reactive oxygen species-independent activation of the IL-1 beta inflammasome in cells from patients with chronic granulomatous disease. Proc Natl Acad Sci USA. 2010;107:3030-3.

31. Horng T. Calcium signaling and mitochondrial destabilization in the triggering of the NLRP3 inflammasome. Trends Immunol. 2014;35:253-61.

32. National Toxicology P. Toxicology and carcinogenesis studies of pyrogallol (CAS No. 87-66-1) in F344/N rats and B6C3F1/N mice (dermal studies). Natl Toxicol Program Tech Rep Ser. 2013;574:1-167.

33. Mercado-Feliciano M, Herbert RA, Wyde ME, Gerken DK, Hejtmancik MR, Hooth MJ. Pyrogallol-associated dermal toxicity and carcinogenicity in F344/N rats and B6C3F1/N mice. Cutan Ocul Toxicol. 2013:32:234-40.

34. Collantes-Fernandez E, Zaballos A, Alvarez-Garcia G, Ortega-Mora LM. Quantitative detection of Neospora caninum in bovine aborted fetuses and experimentally infected mice by real-time PCR. J Clin Microbiol. 2002:40:1194-8.

35. Jin X, Li G, Zhang X, Gong P, Yu Y, Li J. Activation of a Neospora caninum EGFR-like kinase facilitates intracellular parasite proliferation. Front Microbiol. 2017;8:1980.

36. Wang X, Gong P, Zhang X, Li S, Lu X, Zhao C, et al. NLRP3 inflammasome participates in host response to Neospora caninum infection. Front Immunol. 2018;9:1791.

37. Liu X, Lieberman J. A mechanistic understanding of pyroptosis: the fiery death triggered by invasive infection. Adv Immunol. 2017;135:81-117.

38. Wang X, Gong P, Zhang N, Li L, Chen S, Jia L, et al. Inflammasome activation restrains the intracellular Neospora caninum proliferation in bovine macrophages. Vet Parasitol. 2019;268:16-20.

39. Hornung V, Latz E. Critical functions of priming and lysosomal damage for NLRP3 activation. Eur J Immunol. 2010;40:620-3.

40. Patel MN, Carroll RG, Galvan-Pena S, Mills EL, Olden R, Triantafilou M, et al. Inflammasome priming in sterile inflammatory disease. Trends Mol Med. 2017;23:165-80.

41. Place DE, Kanneganti TD. Recent advances in inflammasome biology. Curr Opin Immunol. 2018:50:32-8.

42. Elliott El, Sutterwala FS. Initiation and perpetuation of NLRP3 inflammasome activation and assembly. Immunol Rev. 2015:265:35-52.

43. Jo EK, Kim JK, Shin DM, Sasakawa C. Molecular mechanisms regulating NLRP3 inflammasome activation. Cell Mol Immunol. 2016:13:148-59.

44. Canli O, Nicolas AM, Gupta J, Finkelmeier F, Goncharova O, Pesic M, et al. Myeloid cell-derived reactive oxygen species induce epithelial mutagenesis. Cancer Cell. 2017;32(869-83):e5.

45. Liu Q, Zhang D, Hu D, Zhou X, Zhou Y. The role of mitochondria in NLRP3 inflammasome activation. Mol Immunol. 2018:103:115-24.

46. Gupta AK, Ghosh K, Palit S, Barua J, Das PK, Ukil A. Leishmania donovani inhibits inflammasome-dependent macrophage activation by exploiting the negative regulatory proteins A20 and UCP2. FASEB J. 2017:31:5087-101.

47. Lambeth JD. NOX enzymes and the biology of reactive oxygen. Nat Rev Immunol. 2004:4:181-9.

48. Wu X, Zhang H, Qi W, Zhang Y, Li J, Li Z, et al. Nicotine promotes atherosclerosis via ROS-NLRP3-mediated endothelial cell pyroptosis. Cell Death Dis. 2018;9:171.

49. Lamkanfi M, Dixit VM. Manipulation of host cell death pathways during microbial infections. Cell Host Microbe. 2010;8:44-54. 
50. Moreira-Souza ACA, Almeida-da-Silva CLC, Rangel TP, Rocha GDC, Bellio M, Zamboni DS, et al. The P2X7 receptor mediates Toxoplasma gondii control in macrophages through canonical NLRP3 inflammasome activation and reactive oxygen species production. Front Immunol. 2017:8:1257.

51. Quan JH, Huang R, Wang Z, Huang S, Choi IW, Zhou Y, et al. P2X7 receptor mediates NLRP3-dependent IL-1 beta secretion and parasite proliferation in Toxoplasma gondii-infected human small intestinal epithelial cells. Parasit Vectors. 2018:11:1.

52. Niu J, Wu S, Chen M, Xu K, Guo Q, Lu A, et al. Hyperactivation of the NLRP3 inflammasome protects mice against influenza A virus infection via IL-1 beta mediated neutrophil recruitment. Cytokine. 2019;120:115-24

53. Si H, Xu C, Zhang J, Zhang X, Li B, Zhou X, et al. Licochalcone A: an effective and low-toxicity compound against Toxoplasma gondii in vitro and in vivo. Int J Parasitol Drugs Drug Resist. 2018;8:238-45.

54. Montazeri M, Emami S, Asgarian-Omran H, Azizi S, Sharif M, Sarvi S, et al. In vitro and in vivo evaluation of kojic acid against Toxoplasma gondii in experimental models of acute toxoplasmosis. Exp Parasitol. 2019;200:7-12.

55. Park WH, Park MN, Han YH, Kim SW. Pyrogallol inhibits the growth of gastric cancer SNU-484 cells via induction of apoptosis. Int J Mol Med. 2008:22:263-8.
56. Han YH, Kim SZ, Kim SH, Park WH. Pyrogallol inhibits the growth of lung cancer Calu-6 cells via caspase-dependent apoptosis. Chem Biol Interact. 2009;177:107-14

57. Han YH, Kim SZ, Kim SH, Park WH. Apoptosis in pyrogallol-treated Calu-6 cells is correlated with the changes of intracellular GSH levels rather than ROS levels. Lung Cancer. 2008;59:30-114.

58. Han YH, Kim SH, Kim SZ, Park WH. Pyrogallol inhibits the growth of human pulmonary adenocarcinoma A549 cells by arresting cell cycle and triggering apoptosis. J Biochem Mol Toxicol. 2009;23:36-42.

59. Han BR, Park WH. MAPK inhibitors enhance cell death in pyrogalloltreated human pulmonary fibroblast cells via increasing $\mathrm{O}_{2}(\cdot-)$ levels. Oncol Lett. 2017:14:1179-85.

60. Dey N, Sinha M, Gupta S, Gonzalez MN, Fang R, Endsley JJ, et al. Caspase-1/ASC inflammasome-mediated activation of IL-1 beta-ROS-NFkappaB pathway for control of Trypanosoma cruzi replication and survival is dispensable in NLRP3-/- macrophages. PLoS One. 2014;9:e111539.

\section{Publisher's Note}

Springer Nature remains neutral with regard to jurisdictional claims in published maps and institutional affiliations.
Ready to submit your research? Choose BMC and benefit from:

- fast, convenient online submission

- thorough peer review by experienced researchers in your field

- rapid publication on acceptance

- support for research data, including large and complex data types

- gold Open Access which fosters wider collaboration and increased citations

- maximum visibility for your research: over $100 \mathrm{M}$ website views per year

At BMC, research is always in progress.

Learn more biomedcentral.com/submissions 